\title{
Platelet Thrombospondin Forms a Trimolecular Complex with Plasminogen and Histidine-rich Glycoprotein
}

Roy L. Silverstein, Lawrence L. K. Leung, Peter C. Harpel, and Ralph L. Nachman

Department of Medicine, Division of Hematology-Oncology, and the Specialized Center of Research in Thrombosis,

The New York Hospital-Cornell Medical Center, New York 10021

\begin{abstract}
Thrombospondin (TSP), a multifunctional $\alpha$-granule glycoprotein of human platelets binds fibrinogen, fibronectin, heparin, histidine-rich glycoprotein (HRGP), and plasminogen (Plg), and thus, may play an important role in regulating thrombotic influences at vessel surfaces. In this study we have demonstrated that purified human platelet TSP formed a trimolecular complex with human Plg and HRGP. Complex formation was detected by a specific binding enzyme-linked immunosorbent assay (ELISA) which demonstrated simultaneous binding of fluidphase Plg and HRGP to TSP adsorbed to microtitration wells. While neither ligand inhibited complex formation of the other with TSP, $10 \mathrm{mM}$-amino-n-caproic acid selectively blocked incorporation of Plg into the complex, suggesting that TSP contains independent binding sites for Plg and HRGP. Comparable extent of trimolecular complex formation was also detected when TSP monomer was substituted for whole TSP in the ELISA. HRGP covalently cross-linked to Sepharose 4B simultaneously bound both ${ }^{125} \mathrm{I}-\mathrm{TSP}$ and ${ }^{131} \mathrm{I}-\mathrm{Plg}$, confirming trimolecular complex formation. Rocket immunoelectrophoresis of mixtures of the purified radiolabeled proteins into anti-Plg containing agarose also confirmed trimolecular complex formation. The TSP-HRGP-Plg complex bound a similar amount of heparin as the TSP-HRGP complex, demonstrating that the HRGP within the trimolecular complex maintained functional capability. Similarly, using a fluorometric plasmin substrate, the trimolecular complex was shown to be an effective substrate for tissue plasminogen activator. Significant amounts of plasmin were generated from the TSP-HRGP-Plg complex (equivalent to that from the TSP-PIg complex), but the rate of plasmin generation from the trimolecular complex was greater than from the bimolecular complex, suggesting an important interaction of HRGP with Plg when both are complexed to TSP. The macromolecular assembly of these three proteins on cellular surfaces, such as the platelet, may serve important regulatory functions, both prothrombotic at sites of active fibrin deposition and proteolytic in nonfibrin-containing microenvironments.
\end{abstract}

\section{Introduction}

Thrombospondin (TSP), ${ }^{1}$ a 450,000-mol wt multinodular glycoprotein $(1,2)$, is a major constituent of the platelet $\alpha$-granule

Received for publication 19 September 1984 and in revised form 31 December 1984.

1. Abbreviations used in this paper: AFC, 7-amino-4-trifluoromethyl coumarin; EACA, $\epsilon$-amino-n-caproic acid; ELISA, enzyme-linked im-

J. Clin. Invest.

(C) The American Society for Clinical Investigation, Inc. 0021-9738/85/06/2065/09 \$1.00

Volume 75, June 1985, 2065-2073
$(3,4)$ and becomes surface associated upon platelet stimulation (5). It is also a product of endothelial cells $(6,7)$, fibroblasts (8), and monocytes (9), and is a constituent of the extracellular matrix (8). TSP is a multifunctional molecule that appears to be organized, like fibronectin (10), into discrete functional domains (11-13). The endogenous lectin of human platelets is TSP $(14,15)$ and anti-TSP Fab partially inhibits platelet aggregation (16), suggesting an important role in platelet function. Among other known functions of TSP are the ability to bind specifically with heparin $(1,11)$, fibrinogen (17), fibronectin $(17,18)$, and type $\mathrm{V}$ collagen (19), and thus, perhaps play a role in extracellular matrix organization, cellcell and cell-matrix communication, and modulation of hemostasis.

Recently we have shown that there is a high affinity interaction of TSP with histidine-rich glycoprotein (HRGP) (20) and with plasminogen (Plg) (21). HRGP, an $\alpha 2$-glycoprotein of human plasma (22), is also found in platelet $\alpha$-granules and is secreted upon platelet activation (23). It is a protein of multiple functions, including metal binding and perhaps transport (24), immunoregulation (25), and modulation of hemostasis. HRGP binds heparin with high affinity and neutralizes its anticoagulant effect $(26,27)$; it also binds $\mathrm{Plg}$ via that protein's high affinity lysine-binding site (LBS) (28) and thus may serve as a physiological counterpart to the antifibrinolytic amino acids. The TSP-HRGP complex retains the heparin binding and neutralizing function of HRGP (20), and the TSP-Plg interaction, which is also mediated via the Plg LBS, interferes with the ability of tissue plasminogen activator (TPA) to activate Plg (21) on a fibrin clot. In this paper, we report that TSP can form a trimolecular complex with HRGP and Plg and that the HRGP and Plg within the macromolecular complex retain functional capability. Such functional macromolecular complexes, when assembled on platelet as well as other cellular surfaces, may modulate thrombotic as well as fibrinolytic events.

\section{Methods}

Materials. Electrophoresis grade agarose was purchased from FMC Corp., Rockland, ME. Microtiter plates and a Titertek multiscan photometer were purchased from Flow Laboratories, McLean, VA. Heparin Sepharose CL-4B, cyanogen bromide-activated Sepharose 4B, a Mono $\mathrm{Q}$ anion exchange column, and a fast performance liquid chromatograph (FPLC) were purchased from Pharmacia Fine Chemicals, Piscataway, NJ. The fluorometric plasmin substrate, D-val-leulys-7-amino-4-trifluoromethyl coumarin (AFC), was purchased from

munosorbent assay; FPLC, fast performance liquid chromatography; HRGP, histidine-rich glycoprotein; $k_{\text {cat }}$, catalytic rate constant; LBS, plasminogen lysine binding sites; Plg, plasminogen; SDS-PAGE, sodium dodecyl sulfate-polyacrylamide gel electrophoresis; TPA, tissue plasminogen activator, TSP, thrombospondin; VWF, von Willebrand factor. 
Enzyme Systems Products, Livermore, CA, and a model 650-10S fluorescence spectrophotometer from Perkin-Elmer, Norwalk, CT. Type VII calf mucosal alkaline phosphatase and $p$-nitrophenyl phosphate were purchased from Sigma Chemical Co., St. Louis, MO. G-Amino$n$-caproic acid (EACA) and the calcium ionophore A23187 were purchased from Calbiochem-Behring Corp., La Jolla, CA. ${ }^{35}$ S-heparin, sp act $0.029 \mu \mathrm{Ci} / \mu \mathrm{g}$, was purchased from New England Nuclear, Boston, MA. All reagents were of analytic grade.

Purification of fibrin-free TSP. We have found previously, as have others, that platelet TSP prepared in the standard manner $(1,17)$ often contains small amounts of fibrin detectable by both enzyme-linked immunosorbent assay (ELISA) and sodium dodecyl sulfate-polyacrylamide gel electrophoresis (SDS-PAGE). Since some of the studies reported here involved interactions that could be greatly influenced by the presence of fibrin, it was necessary to prepare TSP that did not contain any contaminating fibrin. Fibrin-free TSP was prepared from four to six units of washed fresh human platelets by the following modifications of the methods of Lawler et al. (1) and Clezardin et al. (29): To prevent fibrin formation during platelet release, platelets were stimulated with calcium ionophore A23187 $(2 \mu \mathrm{M})$, rather than thrombin, in the presence of EDTA and protease inhibitors (17). The releasate was applied to a heparin Sepharose CL-4B affinity column and partially purified TSP eluted with $0.45 \mathrm{M} \mathrm{NaCl}$. This material was diluted $1: 3$ in $20 \mathrm{mM}$ Tris- $\mathrm{HCl}, \mathrm{pH} 7.4$, and applied to a mono Q anion exchange column on an FPLC. Proteins were then eluted with a continuous $\mathrm{NaCl}$ gradient $(0-0.8 \mathrm{M})$ (Fig. 1) and fractions analysed by SDS-PAGE and ELISAs specific for TSP and fibrinogen. TSP eluted at $0.6 \mathrm{M} \mathrm{NaCl}$, while fibrinogen eluted at $\sim 0.3 \mathrm{M}$. Silver stain of a $7.5 \%$ Laemmli slab gel loaded with $10 \mu \mathrm{g}$ of reduced material from the TSP fraction (Fig. 1, inset) showed a single band of $M_{\mathrm{r}} 180,000$ identical to a TSP standard. This fraction was also shown to contain
TSP, but no fibrinogen and $<0.5 \%$ Platelet Factor 4 by separate ELISA specific for these proteins. A radioimmunoassay for $\beta$-thromboglobulin, kindly performed by Dr. John Owen (Columbia University College of Physicians and Surgeons, New York) revealed $<0.07 \% \beta$-thromboglobulin in the TSP fractions.

Reductive alkylation of TSP. A sample of purified TSP was reduced in $3 \% 2$-mercaptoethanol for $3 \mathrm{~h}$ at $22^{\circ} \mathrm{C}$, followed by alkylation in $0.25 \mathrm{M}$ iodoacetamide, $\mathrm{pH} 8.0$, and disruption of noncovalent associations with $4 \mathrm{M}$ urea. This material was then dialyzed against a buffer of $20 \mathrm{mM}$ Tris- $\mathrm{HCl}, 0.15 \mathrm{M} \mathrm{NaCl}, \mathrm{pH} 7.4$, containing $4 \mathrm{M}$ urea. Reduction was confirmed by SDS-PAGE which revealed a single band of $M_{\mathrm{r}} 180,000$ identical to that of TSP monomer.

Purification of other proteins. Purified human native N-terminal glutamine plasminogen (glu-Plg), plasmin, HRGP, von Willebrand Factor (VWF), and fibronectin were prepared as described in detail previously $(17,20,21,30)$. The Plg was free of HRGP and fibrinogen as detected by ELISAs specific for these proteins and the HRGP was similarly free of Plg and fibrinogen. Human melanoma cell line TPA $(90,000 \mathrm{IU} / \mathrm{mg})$ was a generous gift of Dr. Nils Bang, Eli Lilly \& Co., Indianapolis, IN. Bovine serum albumin (BSA) was purchased from Miles Laboratories, Kankakee, IL, and pasteurized nonfat dry milk from Carnation, Inc., Los Angeles, CA. Purified human albumin was purchased from Calbiochem-Behring Corp.

Radioisotope labeling. Purified TSP, HRGP, Plg, and fibrinogen were labeled to high specific activity with ${ }^{125}$ I using the modified chloramine $T$ method (31). For the Sepharose bead binding experiments, purified human albumin and TSP were labeled with ${ }^{125} \mathrm{I}$ and $\mathrm{Plg}$ with

${ }^{131}$ I using $1.5-\mathrm{ml}$ polypropylene tubes (32) coated with iodogen (Pierce Chemical Co., Rockford, IL).

Antisera. Antisera to purified Plg and HRGP were raised in rabbits by standard techniques (33) as described previously $(17,20,21)$. Anti-

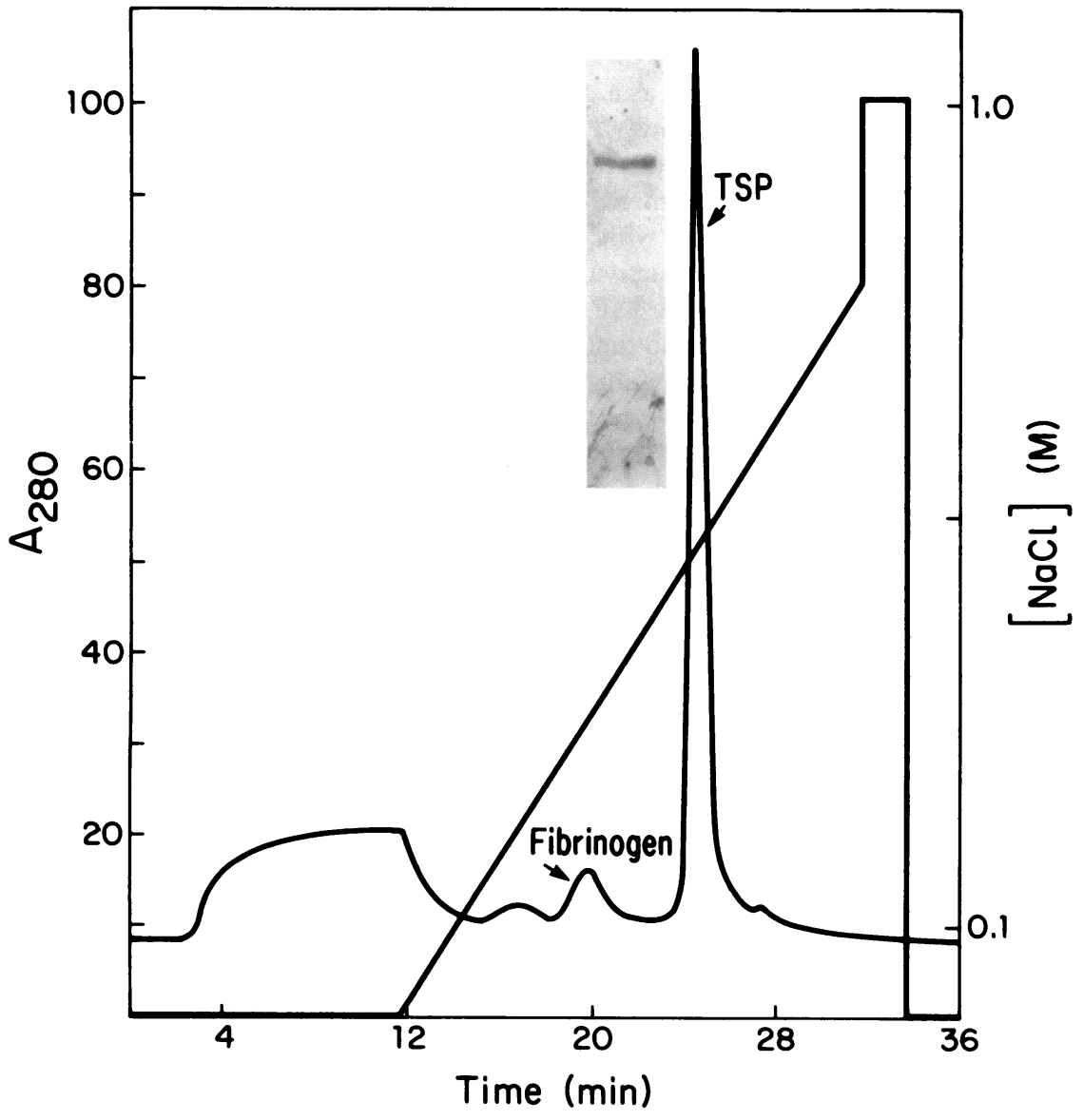

Figure 1. Purification of TSP by FPLC. Elution profile obtained by $0-0.8 \mathrm{M}$ continuous $\mathrm{NaCl}$ gradient from mono $\mathrm{Q}$ anion exchange column. Partially purified TSP from releasate of ionophore-treated platelets was eluted from a Heparin-Sepharose CL-4B column, diluted threefold in $20 \mathrm{mM}$ Tris- $\mathrm{HCl}, \mathrm{pH} \mathrm{7.4,} \mathrm{and} 10$ $\mathrm{ml}$ applied to the mono $\mathrm{Q}$ column via a $10-\mathrm{ml}$ "superloop." Tracing shows relative protein concentration determined as a relative $O D$ 280. Insert shows silver stain of 7.5\% SDSPAGE of protein from TSP peak. Approximately $10 \mu \mathrm{g}$ of protein was loaded on the gel. 
Plg did not react by ELISA with fibrinogen, IgG, albumin, fibronectin, HRGP, TSP, or VWF. Anti-HRGP similarly did not react with fibrinogen, VWF, IgG, albumin, Plg, fibronectin, or TSP. Alkaline phosphatase conjugated $\mathrm{Fab}_{2}^{\prime}$ was prepared as described previously $(20,21)$.

ELISA demonstration of complex formation. Assays were performed according to the method of Voller et al. (34) as previously described $(17,20,21)$. Microtitration plates were coated with purified TSP or monomeric TSP in coating buffer for $3 \mathrm{~h}$ at $37^{\circ} \mathrm{C}$. In the latter experiments $4 \mathrm{M}$ urea was included in the coating buffer to maintain TSP in the monomeric state. The wells were then washed three times in a Tris-Tween-calcium buffer ( $20 \mathrm{mM}$ Tris- $\mathrm{HCl}, 0.15 \mathrm{M} \mathrm{NaCl}, 1.5$ $\mathrm{mM} \mathrm{CaCl}{ }_{2}, 0.05 \%$ Tween $20, \mathrm{pH} \mathrm{7.4)}$ and then mixtures of purified $\mathrm{Plg}$ and HRGP were added in duplicate (diluted in the same buffer) for $18 \mathrm{~h}$ at $4^{\circ} \mathrm{C}$. After washing to remove unbound ligands, alkaline phosphatase conjugated anti-Plg Fab or anti-HRGP Fab' were added in parallel wells. After incubation for $3 \mathrm{~h}$ at $37^{\circ} \mathrm{C}$ followed by washing, the substrate $p$-nitrophenyl phosphate was added and color development followed by repeated readings in a multichannel photometer. The formation of the complex was expressed as the enzymatic activity of the bound alkaline phosphatase ( $\Delta$ absorbance [A] $405 \mathrm{~nm} \cdot \mathrm{min}^{-1}$ ).

Protein binding to HRGP-linked Sepharose $4 B$. HRGP or human albumin, $2 \mathrm{mg}$, were covalently coupled to $1 \mathrm{ml}$ cyanogen bromideactivated Sepharose 4B, as previously described (16). Efficiency of coupling was $>95 \%$ as determined by measuring protein concentrations of the coupling solutions before and after the cross-linking reaction. After incubating the beads in $1 \mathrm{ml}$ of the Tris-Tween-calcium buffer containing $0.1 \% \mathrm{BSA}$ for $1 \mathrm{~h}$ at $37^{\circ} \mathrm{C}$ to saturate nonspecific protein binding sites, aliquots containing $3 \mu \mathrm{l}$ of the beads were removed, washed with buffer, and incubated with $0.5 \mathrm{ml}$ Tris-Tween-calcium containing either ${ }^{125} \mathrm{I}$-TSP $\left(4 \mu \mathrm{g} / \mathrm{ml} ; 12 \times 10^{3} \mathrm{cpm} / \mu \mathrm{g}\right),{ }^{131} \mathrm{I}-\mathrm{Plg}(12$ $\mu \mathrm{g} / \mathrm{ml} ; 14 \times 10^{3} \mathrm{cpm} / \mu \mathrm{g}$ ), or both for $3 \mathrm{~h}$ at $37^{\circ} \mathrm{C}$. The beads were then washed five times with $1 \mathrm{ml}$ of the buffer and total bound radioactivity counted in a dual channel gamma counter. The beads were then incubated with $10 \mathrm{mM}$ EACA for $2 \mathrm{~h}$ at $37^{\circ} \mathrm{C}$ and the eluted material counted. Nonspecific binding was defined as the amount of ${ }^{125} \mathrm{I}$-TSP and/or ${ }^{131} \mathrm{I}$-Plg bound to the same volume of albumin-coupled beads. The binding of ${ }^{125} \mathrm{I}$-albumin $(12 \mu \mathrm{g} / \mathrm{ml} ; 14$ $\left.\times 10^{3} \mathrm{cpm} / \mu \mathrm{g}\right)$ to the HRGP beads was also determined as another measure of specificity. In those experiments, the buffer contained $5 \%$ nonfat dry milk instead of BSA. In all experiments, the washing steps were done by low speed centrifugation $(900 \mathrm{~g})$ through a porous filter. All experiments were done in triplicate.

Rocket immunoelectrophoresis. Agarose stocks were prepared by melting electrophoresis grade agarose in $0.05 \mathrm{M}$ phosphate buffer, $\mathrm{pH}$ 7.4 , at a concentration of $1 \%$. The melted agarose was cooled to $45^{\circ} \mathrm{C}$ and mixed with prewarmed monospecific anti-Plg antiserum (final concentration, $0.08 \%$ ). $3-5 \mathrm{ml}$ of this antibody-agarose mixture was layered onto glass microscope slides and antigen samples consisting of either TSP, Plg, HRGP, or combinations thereof were applied in 20 $\mathrm{mM}$ Tris- $\mathrm{HCl}, 0.15 \mathrm{M} \mathrm{NaCl}, 1.5 \mathrm{mM} \mathrm{CaCl}_{2}, \mathrm{pH} \mathrm{7.4,} \mathrm{to} \mathrm{4-mm} \mathrm{diam}$ wells. The individual slides were subjected to $50 \mathrm{~V}$ and $3 \mathrm{~mA}$ for 20 $\mathrm{h}$ at $22^{\circ} \mathrm{C}$. Following electrophoresis, the slides were washed exhaustively with saline containing $0.1 \%$ azide followed by 30 -min distilled water wash, dried, and stained with $1 \%$ amido black in $40 \%$ ethanol/10\% acetic acid and destained in $90 \%$ methanol $/ 5 \%$ acetic acid. For all studies, the amount of Plg was held constant and for the mixture studies, the mole ratios were fixed at 3:3:1 for Plg/HRGP/TSP.

Fluorometric plasmin assay. To TSP adsorbed on plastic microtiter wells (as in ELISA studies) was added mixtures of Plg and HRGP in the Tris-Tween-calcium buffer. After washing away unbound ligands, $0.3 \mathrm{ml}$ of substrate buffer was added containing $10 \mu \mathrm{M} \mathrm{D}$-val-leu-lysAFC and $5 \mathrm{U} / \mathrm{ml}$ TPA (in the same Tris-Tween-calcium). At timed intervals, well contents were removed and substrate hydrolysis measured at excitation of $400 \mathrm{~nm}$ and emission of $505 \mathrm{~nm}$. The increase of fluorescence, measured as relative fluorescence units (RFU), was parabolic with time conforming to the equation for rectilinear motion with constant acceleration (35). The relative initial rates of plasmin generation, which are directly proportional to the acceleration, were determined according to the method of Kosow et al. (36) from plots of RFU vs. $t^{2}$ at time points early in the course of substrate hydrolysis. These plots were calculated using a least squares linear regression estimation. The amount of plasmin generated was estimated by comparing the slopes of the terminal portions of the hydrolysis curves (by which time activation of Plg was nearly complete) to those of plasmin standard curves. For the experiments done to calculate kinetic parameters, TSP was adsorbed to the plates as above, but TPA and the plasmin substrate were added directly with the Plg. By eliminating the washing step, Plg concentrations were controlled, allowing determination of kinetic parameters. Fluid-phase activation kinetics were determined as above using the fluorometric plasmin substrate and nonprotein-coated microtiter wells. The rate of Plg activation in the presence of fibrin was measured with a ${ }^{125}$ I-fibrin plate assay described previously $(21,37)$. In this assay Plg was activated in polystyrene wells coated with $6.5 \mu \mathrm{g} / \mathrm{ml}$ clotted ${ }^{125}$ I-fibrinogen. The substrate did not undergo spontaneous hydrolysis in these studies nor did TPA hydrolyze the substrate in the absence of Plg.

${ }^{35}$ S-Heparin binding studies. Plg and HRGP were complexed to TSP in microtiter wells as described above and then incubated with ${ }^{35} \mathrm{~S}$-heparin for $1 \mathrm{~h}$ at $37^{\circ} \mathrm{C}$. After extensive washing to remove unbound heparn, the well contents were solubilized in 2\% SDS for 4 $h$ and counted in a liquid scintillation counter.

\section{Results}

ELISA demonstration of TSP-Plg-HRGP complex formation. The ELISA binding assay demonstrated that TSP passively adsorbed to wells of a plastic microtitration plate simultaneously bound both Plg and HRGP, thereby forming a trimolecular complex. The extent of binding was quantified by the enzymatic activity of the bound alkaline phosphatase conjugated $\mathrm{Fab}_{2}^{\prime}$ fragments of anti-Plg or anti-HRGP and was expressed as percent of maximal binding in the absence of the second ligand. Binding of TSP to each of the ligands (Plg or HRGP) individually was saturable (Fig. $2 A$ and $B$, open triangles) with apparent dissociation constant $\left(K_{\mathrm{D}}\right)$ of 35 and $12.5 \mathrm{nM}$, respectively. Specificity of these interactions has been previously shown $(20,21)$ by inhibition with excess fluid-phase TSP and by lack of detectable binding of Plg or HRGP to a variety of other adsorbed proteins as well as lack of binding of adsorbed TSP to multiple other fluid-phase proteins. When HRGP and $\mathrm{Plg}$ were incubated together in the TSP-coated ELISA wells and binding of each ligand measured in parallel wells, both proteins could be detected on the TSP. The family of saturable binding curves in Fig. $2 A$ show that TSP-Plg binding was not inhibited in the presence of fluid-phase HRGP. Similarly, the curves in Fig. $2 B$ show that TSP-HRGP binding was not inhibited in the presence of fluid-phase Plg. In both sets of experiments, slight augmentation of complex formation occurred at the higher concentrations of second ligand.

TSP monomer was substituted for whole TSP in the ELISA studies and saturable specific binding to Plg and HRGP was also observed. The maximum extent of binding was similar to that of whole nonreduced TSP as were the approximate $K_{\mathrm{D}}$ 's of 35 and $12.5 \mathrm{nM}$. Table I shows that, as with whole nonreduced TSP, Plg binding was detected when Plg was incubated in the wells in the presence of supersaturating concentrations of HRGP, and HRGP binding was also detected when incubated with supersaturating concentrations of Plg. At the highest concentration of HRGP tested $\left(8 \times K_{\mathrm{D}}\right)$, there was slight $(20 \%)$ inhibition of Plg binding.

Similarly, when calcium-replete TSP (prepared in the stan- 


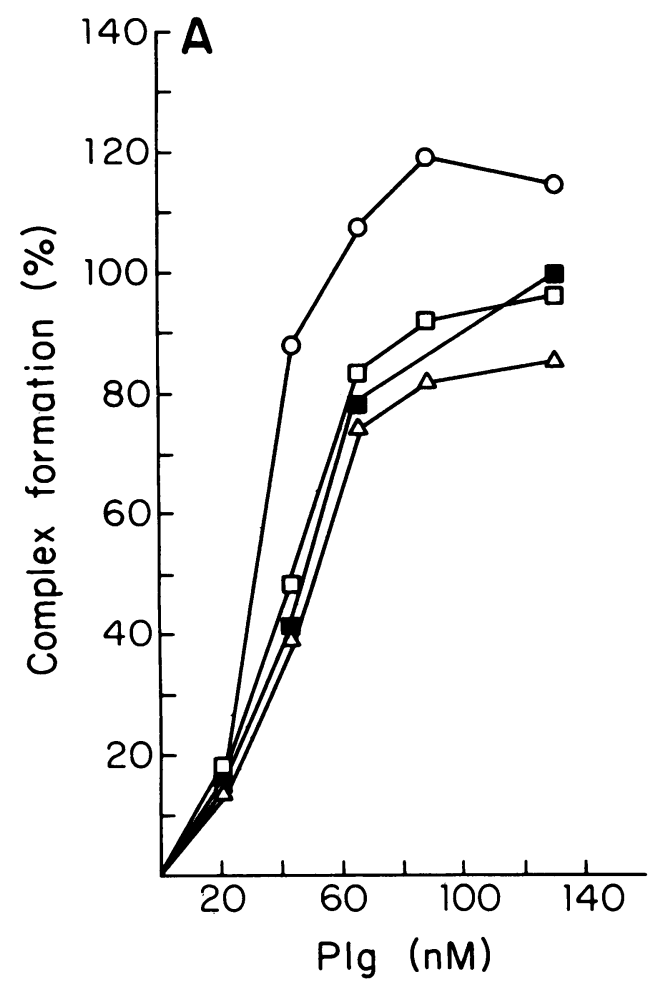

Figure 2. ELISA demonstration of TSP-HRGP-Plg complex formation. TSP ( $4 \mu \mathrm{g} / \mathrm{ml})$ in coating buffer was applied to plastic wells for $3 \mathrm{~h}$ at $37^{\circ} \mathrm{C}$. After washing, $(A) \mathrm{Plg}$ was added in the presence of fluid-phase HRGP $(\triangle, 0 \mathrm{nM} ; \bullet, 25 \mathrm{nM} ; \square, 50 \mathrm{nM} ; \circ, 100 \mathrm{nM})$ for 18 $h$ at $4^{\circ} \mathrm{C}$ or $(B)$ HRGP was added in the presence of fluid-phase Plg $(\triangle, 0 \mathrm{nM} ; \approx, 44 \mathrm{nM} ; \square, 66 \mathrm{nM} ; 0,88 \mathrm{nM})$. After washing, alkaline

dard manner by substituting $1 \mathrm{mM} \mathrm{CaCl}{ }_{2}$ in all buffers for EDTA) was substituted for the standard TSP preparation in the ELISA binding assay, the extent of binding to Plg and HRGP was not changed (data not shown).

When the two ligands were added at saturating concentrations to either whole TSP or monomeric TSP in the presence

Table I. ELISA Demonstration of Trimolecular Complex Formation of Monomeric TSP with Plg and HRGP

\begin{tabular}{lllc}
\hline & & \multicolumn{2}{l}{$\begin{array}{l}\text { Percent complex formation } \\
\text { detected with: }\end{array}$} \\
\cline { 3 - 4 } Ligand I $(n M)$ & Ligand II $(n M)$ & Antiligand I & Antiligand II \\
\hline HRGP (12.5) & Plg (0) & 100 & 0 \\
HRGP (12.5) & $\operatorname{Plg}(110)$ & 117 & 100 \\
HRGP (12.5) & $\operatorname{Plg}(210)$ & 137 & 100 \\
HRGP (0) & $\operatorname{Plg}(50)$ & 0 & 100 \\
HRGP (50) & $\operatorname{Plg}(50)$ & 100 & 98 \\
HRGP (100) & $\operatorname{Plg}(50)$ & 100 & 78 \\
\end{tabular}

Ligands were added in fluid phase to microtitration plates to which reduced monomeric TSP $(4 \mu \mathrm{g} / \mathrm{ml})$ had been previously adsorbed. After washing, complex formation was detected as the extent of binding of alkaline phosphatase-conjugated monospecific anti-HRGP (ligand I) or in separate wells, anti-Plg (ligand 2) $\mathrm{Fab}_{2}^{\prime}$. Complex formation is expressed as percent of maximal binding in the absence of the competing ligand.

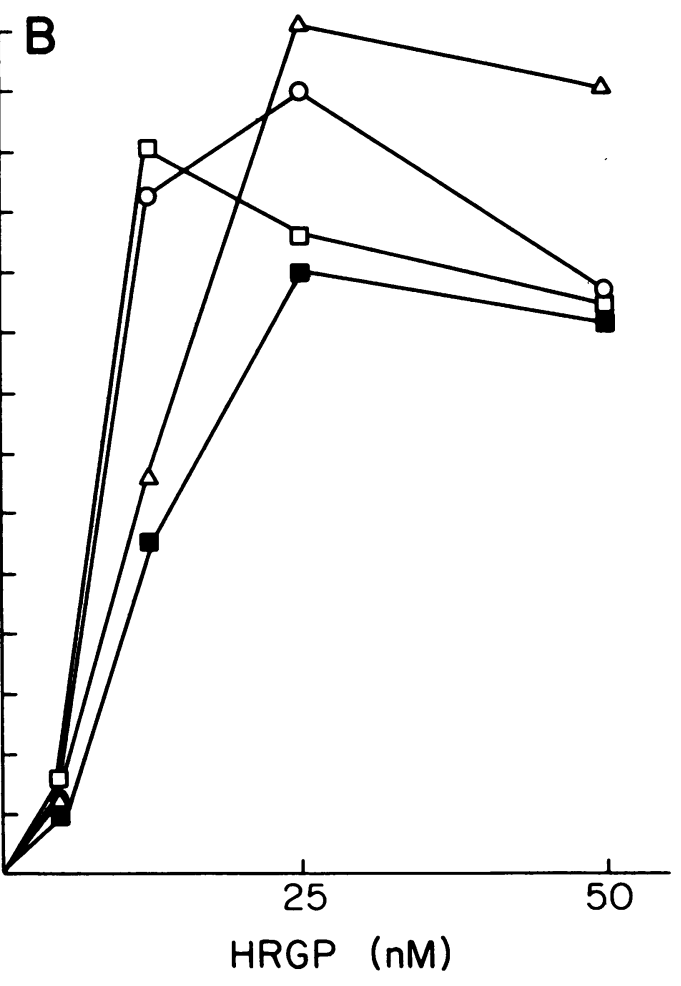

phosphatase-conjugated anti-Plg $(A)$ or anti-HRGP $(B) \mathrm{Fab}_{2}^{\prime}$ were added and complex formation quantified as the enzymatic activity of the bound alkaline phosphatase $\left(10^{4} \times \Delta \mathrm{A} 405 \mathrm{~nm} \times \mathrm{min}^{-1}\right)$. Binding was expressed as percent of maximal binding observed in the absence of the competing ligand.

of 1 mM EACA, Plg binding was nearly completely abolished (7\% of normal), while HRGP binding was not affected (93\% of normal).

Trimolecular complex formation on HRGP-linked Sepharose beads. HRGP covalently cross-linked to cyanogen bromideactivated Sepharose $4 \mathrm{~B}$ specifically bound ${ }^{\mathrm{i} 25} \mathrm{I}-\mathrm{TSP}$ or ${ }^{131} \mathrm{I}-\mathrm{Plg}$ when incubated independently with the two ligands. Specific binding, shown in Table II, was calculated as total protein bound minus nonspecific protein binding as defined in Methods. The beads did not bind ${ }^{125} \mathrm{I}$-albumin, demonstrating further specificity of this assay. Table II shows that when the beads

Table II. Binding of Plg and TSP by HRGP-linked Sepharose Beads

\begin{tabular}{llllll}
\hline & \multicolumn{2}{l}{ Protein bound } & & & \multicolumn{2}{l}{ Eluted by EACA } \\
\cline { 2 - 3 } \cline { 5 - 6 } Beads plus & Plg & TSP & & Plg & TSP \\
\hline & $n g \pm S E$ & $n g \pm S E$ & & $\% \pm S E$ & $\% \pm S E$ \\
Plg & $410 \pm 74$ & - & & $90 \pm 3.5$ & - \\
TSP & - & $96 \pm 8$ & & - & $12.2 \pm 3.4$ \\
Plg \pm TSP & $360 \pm 75$ & $105 \pm 6.7$ & & $94 \pm 3.8$ & $42.4 \pm 3.7$
\end{tabular}

Beads $(3 \mu \mathrm{l})$ were incubated with ${ }^{125} \mathrm{I}-\mathrm{TSP}(2 \mu \mathrm{g})$ and/or ${ }^{131} \mathrm{I}-\mathrm{Plg}(6$ $\mu \mathrm{g})$ for $3 \mathrm{~h}$ at $37^{\circ} \mathrm{C}$, washed five times in buffer, and then counted in a dual channel gamma counter to quantitate bound material. After counting, they were incubated in $10 \mathrm{mM}$ EACA for $2 \mathrm{~h}$ at $37^{\circ} \mathrm{C}$ and then, the eluate was counted. 
were co-incubated with ${ }^{125} \mathrm{I}$-TSP and ${ }^{131} \mathrm{I}-\mathrm{Plg}$, both ligands simultaneously bound, demonstrating trimolecular complex formation. As in the ELISA, no inhibition of one ligand toward the other was seen. EACA $(10 \mathrm{mM})$ eluted $90 \%$ of the bound Plg from the HRGP-Plg complexes but only $12.4 \%$ of the bound TSP from the HRGP-TSP complexes. EACA, however, eluted $42.6 \%$ of the TSP from the trimolecular HRGP-Plg-TSP complexes; i.e., there appeared to be two pools of TSP within these trimolecular complexes, an EACA elutable pool and an EACA nonelutable pool $(P<0.05)$.

Demonstration of TSP-Plg-HRGP complex formation by rocket immunoelectrophoresis. Another system was devised to study trimolecular complex formation based on immunoprecipitation in agar $(38,21)$. Rocket immunoelectrophoresis of mixtures of the three proteins (TSP, Plg, and HRGP) into anti-Plg containing agar was performed. As we have previously reported (21), radiolabeled Plg mixed with TSP (molar ratio, 3:1) and electrophoresed into anti-Plg-containing agar migrated more rapidly than Plg alone and formed an anodally moving, sharp peak that contained Plg as detected both by immunoprecipitation with specific antibody and by autoradiography (Fig. 3, wells 1 and 2). We have shown previously that radiolabeled TSP was also demonstrable in this rapidly moving anodal immunoprecipitin arc (21); i.e., a bimolecular TSP-Plg complex was immunoprecipitated. We now show that when HRGP was included in the TSP-Plg mixture the same rapidly moving anodal Plg arc was formed (Fig. 3, well 3). To demonstrate that this immunoprecipitin arc contained the individual constituents of the trimolecular complex, studies were performed in which each of the ligands was separately radiolabeled. Fig. 4, wells 2, 3, and 4 show an autoradiograph of such a study. Each of these three wells contained the same molar ratio of TSP:HRGP:Plg (1:3:3), but in well 2 the Plg was labeled, in well 3 the TSP was labeled, and in well 4 the HRGP was labeled. All three arcs were radioactive demonstrating that all three proteins (i.e., a trimolecular complex) were immunoprecipitated by the anti-Plg antibody agar. TSP or HRGP alone or the TSP-HRGP complex, as expected, were not precipitated in the anti-Plg agar. The bimolecular PlgHRGP complex was detected by this system (Fig. 4, well 5) and could easily be distinguished from the trimolecular TSPPlg-HRGP complex because its mobility was slightly decreased compared with Plg alone. We have previously shown that Plg mixed with albumin, gammaglobulin, or factor VIII-related antigen (VIIIR:Ag) at similar molar ratios to that employed with TSP showed no alteration in mobility by rocket immunoelectrophoresis (21).

Functionality of the TSP-HRGP-Plg complex. To examine whether Plg and HRGP retained functional capability as part of a trimolecular complex with TSP, we studied the ability of the complex to bind heparin (a function of HRGP) and to serve as a substrate for plasmin generation by the action of TPA (a function of Plg). Complexes of TSP with saturating amounts of Plg, HRGP, or both together were prepared on microtiter plates as described above and either incubated with ${ }^{35} \mathrm{~S}$-heparin to quantify heparin binding or with TPA and a fluorometric plasmin substrate to quantify plasmin generation.

The TSP-HRGP-Plg complex bound equivalent amounts of heparin as the TSP-HRGP complex $(0.83 \mathrm{ng} /$ well $)$ and more than TSP alone or the TSP-Plg complex (Table III), demonstrating that HRGP retained functional capacity within the trimolecular complex.

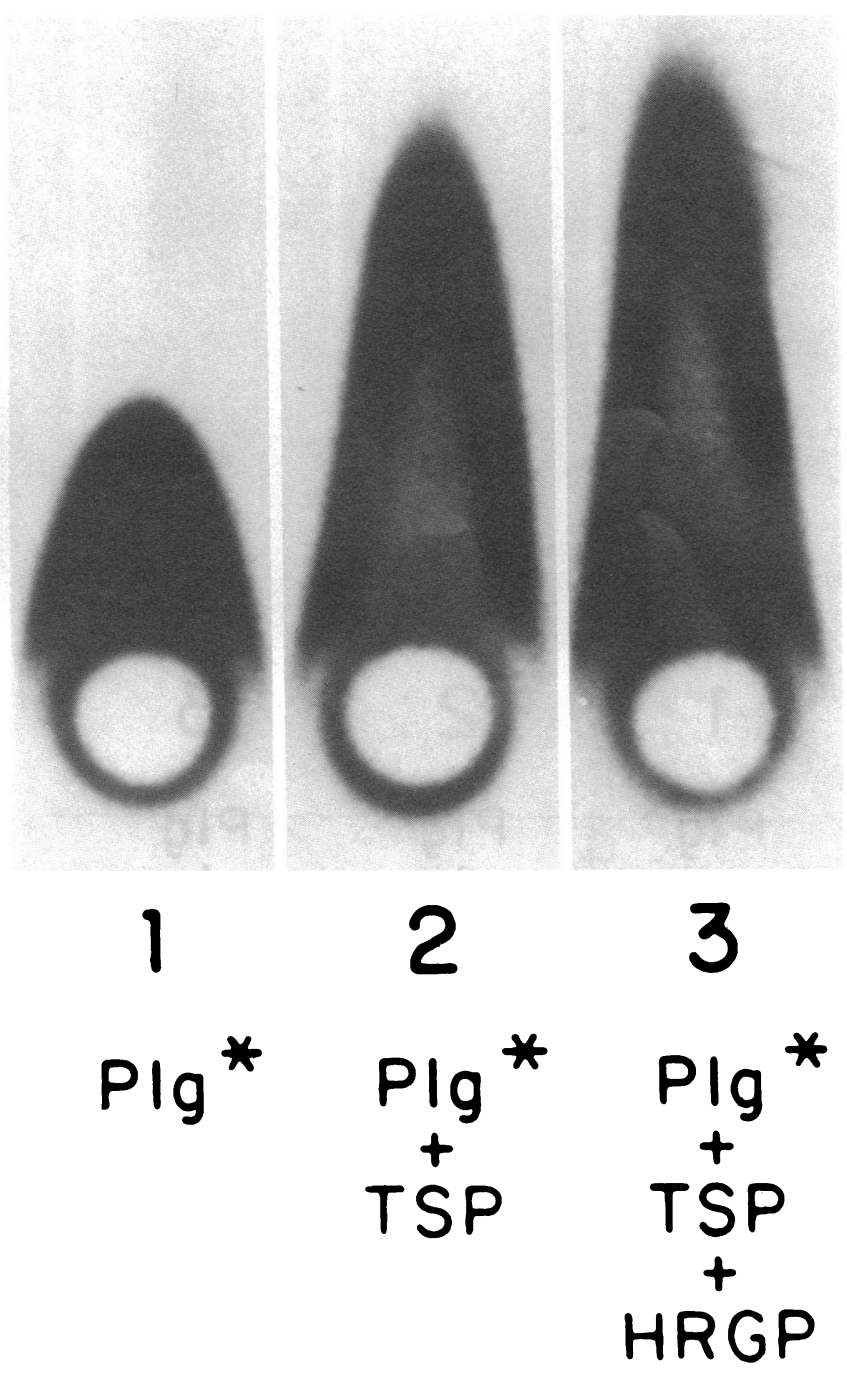

Figure 3. Complex formation of Plg with TSP and Plg with TSP and HRGP demonstrated by rocket immunoelectrophoresis into agarose containing $0.08 \%$ monospecific anti-Plg serum. Figure shows an autoradiograph of three immunoprecipitates. Well 1 contained ${ }^{125}$ I-Plg (3 $\left.\mu \mathrm{g} ; 10^{4} \mathrm{cpm} / \mu \mathrm{g}\right)$, well 2 contained ${ }^{125} \mathrm{I}-\mathrm{Plg}(3 \mu \mathrm{g})$ plus TSP $(6 \mu \mathrm{g})$, and well 3 contained ${ }^{125} \mathrm{I}-\mathrm{Plg}(3 \mu \mathrm{g})$ plus TSP $(6 \mu \mathrm{g})$ plus HRGP $(3 \mu \mathrm{g})$.

TPA $(5 \mathrm{U} / \mathrm{ml})$ generated significant amounts of plasmin from the TSP-Plg complex (Fig. 5). No plasmin was generated from the TSP-HRGP complex and only minimal amounts from Plg added to other adsorbed proteins (fibronectin and VWF). The amount of plasmin generated from the TSP-PlgHRGP complex was equivalent to that from the TSP-Plg complex, demonstrating that Plg retained functional capacity within the trimolecular complex. When the complexes (either TSP-Plg or TSP-HRGP-Plg) were saturated with Plg, $2.6 \mathrm{ng}$ of plasmin was generated (Fig. 5). This represents an activation of $\sim 20 \%$ of the bound Plg (determined from ${ }^{125} \mathrm{I}-\mathrm{Plg}$ binding studies). When the complexes were activated by $20 \mathrm{U} / \mathrm{ml}$ streptokinase (data not shown), similar amounts of plasmin were generated. At all concentrations of Plg tested (up to 100 $\mathrm{nM})$ and all concentrations of HRGP tested (10-50 nM), the rate of plasmin generation from the trimolecular TSP-HRGPPlg complex was faster than from the TSP-Plg bimolecular complex; i.e., the parabolic hydrolysis curves were shifted to 


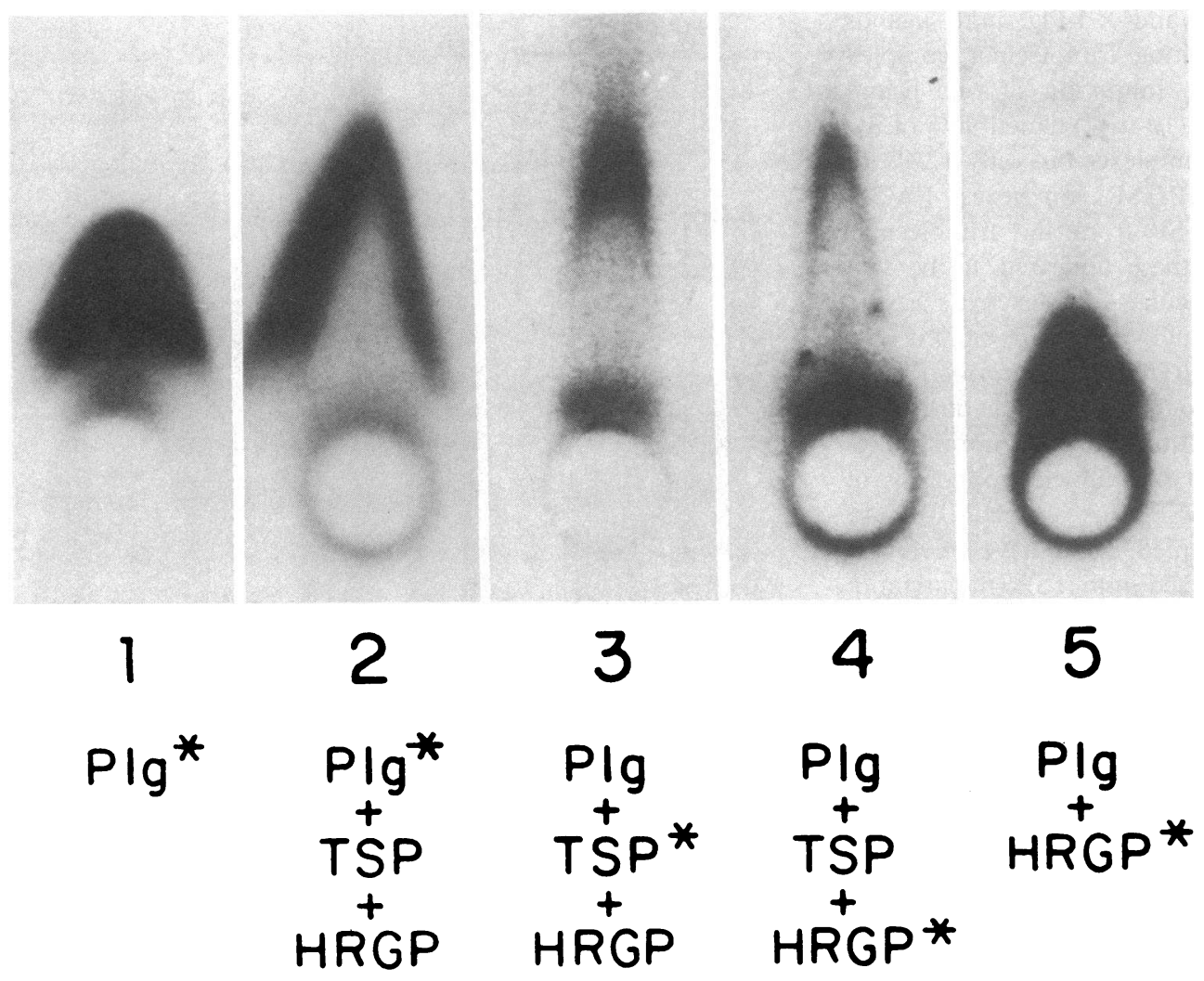

Figure 4. Trimolecular complex formation of TSP with Plg and HRGP demonstrated by rocket immunoelectrophoresis into anti-Plg-containing agarose. Figure shows an autoradiograph of five immunoprecipitates. Well 1 contained ${ }^{125} \mathrm{I}-\mathrm{Plg}(3 \mu \mathrm{g}$; $10^{4} \mathrm{cpm} / \mu \mathrm{g}$ ), wells 3,4 , and 5 contained a mixture of TSP (6 $\mu \mathrm{g}$ ), Plg (3 $\mu \mathrm{g})$, and HRGP $(3 \mu \mathrm{g})$. In well 2 the Plg was radioiodinated $\left(10^{4} \mathrm{cpm} / \mu \mathrm{g}\right)$, in well 3 the TSP was radioiodinated $\left(0.5 \times 10^{4}\right.$ $\mathrm{cpm} / \mu \mathrm{g}$ ), and in well 4 the HRGP was radioiodinated $\left(10^{4} \mathrm{cpm} / \mu \mathrm{g}\right)$. Well 5 contained $\mathrm{Plg}$ (3 $\mu \mathrm{g})$ plus ${ }^{125} \mathrm{I}-\mathrm{HRGP}(3$ $\mu \mathrm{g})$.

the left (Fig. 6). When the complex was saturated with HRGP (50 $\mathrm{nM}$ HRGP), the relative initial reaction rate was increased by 1.8 -fold at $4 \mu \mathrm{g} / \mathrm{ml} \mathrm{Plg}$ and 1.6-fold at $8 \mu \mathrm{g} / \mathrm{ml} \mathrm{Plg}$. These increases were found to be significant at $P<0.025$ using a two-way analysis of variance.

Kinetic parameters were obtained to demonstrate the ability of TSP to promote Plg activation by TPA. Initial reaction rates were calculated as described above on TSP-coated microtiter wells and Lineweaver-Burke transformations plotted using a least squares linear regression estimation. These data (Table IV) show that compared with fluid phase, the Michaelis constant $\left(K_{\mathrm{M}}\right)$ of activation is markedly decreased, so that even though the catalytic rate constant $\left(k_{\text {cat }}\right)$ is only minimally increased, the overall catalytic efficiency $\left(k_{\text {cat }} / K_{\mathrm{M}}\right)$ is increased by 35 -fold. At physiological $\mathrm{Plg}$ concentrations $(\sim 2 \mu \mathrm{M})$, complete saturation would occur at this $K_{\mathrm{M}}$.

Table III. ${ }^{35}$ S-Heparin Binding to TSP-HRGP-Plg Complex

\begin{tabular}{lll}
\hline $\begin{array}{l}\text { Adsorbed protein } \\
(4 \mu g / m l)\end{array}$ & $\begin{array}{l}\text { Complexed ligand } \\
(4 \mu g / m l)\end{array}$ & Heparin bound \\
\hline & & $n g /$ well \\
TSP & - & 0.437 \\
Plg & - & 0.060 \\
TSP & Plg & 0.329 \\
TSP & HRGP & 0.859 \\
TSP & HRGP + Plg & 0.829 \\
\hline
\end{tabular}

Proteins were adsorbed to plastic wells in coating buffer for $18 \mathrm{~h}$ at $4^{\circ} \mathrm{C}$. After washing, buffer or ligands were added for $4 \mathrm{~h}$ at $37^{\circ} \mathrm{C}$. After washing again, ${ }^{35} \mathrm{~S}$-heparin was added for $1 \mathrm{~h}$ at $37^{\circ} \mathrm{C}$. After washing, well contents were solubilized in SDS and radioactivity measured. Data represents mean values from two separate studies, each done in duplicate.

\section{Discussion}

We have shown recently that platelet TSP can bind with HRGP and that this TSP-HRGP complex retains the heparin binding and neutralizing function of HRGP (20). In addition, we have recently shown that TSP can also bind specifically with Plg and that this interaction, which is mediated by the

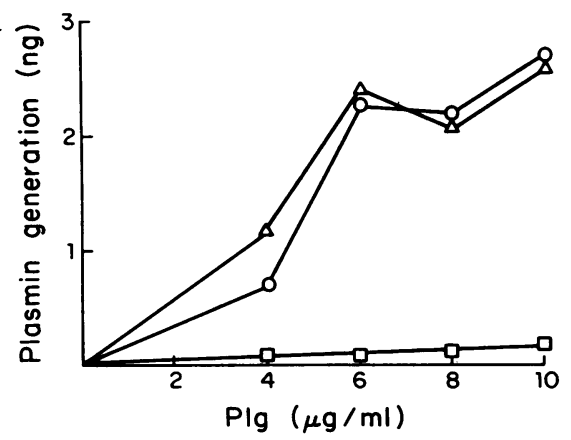

Figure 5. Plasmin generated from TSP-HRGP-Plg complex by TPA. TSP was applied to plastic wells in coating buffer for $18 \mathrm{~h}$ at $4^{\circ} \mathrm{C}$. After washing, Plg in presence $(\Delta)$ or absence $(0)$ of HRGP $(4 \mu \mathrm{g} / \mathrm{ml})$ was added for $4 \mathrm{~h}$ at $37^{\circ} \mathrm{C}$. After washing away unbound ligands, substrate buffer containing the fluorimetric plasmin substrate D-valleu-lys-AFC $(10 \mu \mathrm{M})$ and TPA $(5 \mu \mathrm{m} / \mathrm{ml})$ was added and, at timed intervals, wells were emptied and their contents transferred to cuvettes to measure substrate hydrolysis (fluorescence). Plasmin generation was calculated by comparing the terminal steady state rate of change of fluorescence to plasmin standard curves. Open squares ( $\square$ ) summarize data from control studies in which Plg in the presence or absence of HRGP $(4 \mu \mathrm{g} / \mathrm{ml})$ was added to wells previously coated with fibronectin or VWF instead of TSP. 


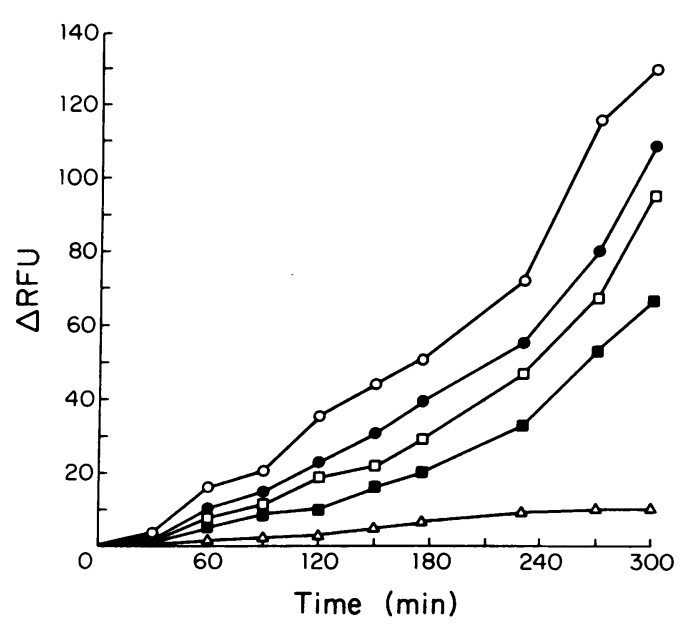

Figure 6. Activation of complexed Plg by TPA. Bimolecular and trimolecular complexes of Plg with TSP or Plg and HRGP with TSP were made on plastic microtitration plates as described for Fig. 5 . The Plg in these complexes was then activated with TPA $(5 \mathrm{U} / \mathrm{ml})$ in the presence of the fluorometric plasmin substrate, D-val-leu-lys-AFC, and, at timed intervals, wells were emptied and their contents transferred to cuvettes to measure substrate hydrolysis (expressed as relative fluorescence units [RFU]). Closed squares ( $\square$ ) and circles (๑) depict substrate hydrolysis by $\mathrm{Plg}$ at $4 \mu \mathrm{g} / \mathrm{ml}$ and $8 \mu \mathrm{g} / \mathrm{ml}$, respectively, added to TSP-coated wells, while open squares $(\square)$ and circles (O) depict substrate hydrolysis by those concentrations of Plg in the presence of HRGP $(4 \mu \mathrm{g} / \mathrm{ml})$. The open triangles $(\Delta)$ depict substrate hydrolysis by $\mathrm{Plg}(8 \mu \mathrm{g} / \mathrm{ml})$ added to wells coated with the control proteins fibronectin or VWF.

LBS, can, in a fibrin-containing environment, inhibit TPA activity (21). It is possible that TSP could serve as an assembly site for these macromolecules (and others) by localizing them to particular microenvironments (such as on an activated platelet surface). Such multimolecular complexes could serve important regulatory functions, for example, by increasing local concentrations of active substances, providing protection from circulating inhibitors, or facilitating the interaction between bound substances.

In this study we present direct evidence using three independent systems that human platelet TSP formed a trimolecular complex with HRGP and Plg. With ELISA binding assays we have shown that when Plg and HRGP were co-incubated with TSP adsorbed to microtitration wells, simultaneous complex formation with both was detected (Fig. 2). Neither ligand

Table IV. Kinetic Parameters of Plg Activation by TPA on Protein-coated Surfaces

\begin{tabular}{llll}
\hline Protein surface & $K_{\mathrm{M}}$ & $k_{\text {cat }}$ & $k_{\text {cad }} / K_{\mathrm{M}}$ \\
\hline & $\mu M$ & $\mathrm{~s}^{-1}$ & $\mu \mathrm{m}^{-1} \cdot \mathrm{s}^{-1}$ \\
None & 3.0 & 0.0005 & 0.0002 \\
Fibrin & 0.1 & 0.008 & 0.08 \\
TSP & 0.085 & 0.0005 & 0.006
\end{tabular}

Fluid-phase activation was carried out in uncoated polystyrene microtiter wells using the fluorometric plasmin substrate D-val-leu-lysAFC. Activation on fibrin or TSP surfaces was carried out in polystyrene wells coated with either ${ }^{125} \mathrm{I}$-fibrin $(6.5 \mu \mathrm{g} / \mathrm{ml})$ or TSP $(4 \mu \mathrm{g} / \mathrm{ml})$. For the former, activation was quantified by measuring release of radiolabeled fibrin degradation products and for the latter, by measuring hydrolysis of the fluorometric plasmin substrate. inhibited complex formation of the other with TSP, and at supersaturating concentrations of the separate ligands, augmentation of binding was seen. Since HRGP and Plg can form a bimolecular complex (28), this augmentation may be due to the binding of each ligand to both TSP and to the other ligand complexed to TSP, i.e., a piggyback effect. The lack of inhibition of the TSP-Plg interaction by excess HRGP and of the TSPHRGP interaction by excess $\mathrm{Plg}$ as well as the selective inhibition of Plg binding by EACA strongly suggests that TSP contains independent binding sites for Plg and HRGP.

We have also demonstrated that HRGP-linked Sepharose beads bound both ligands when co-incubated with ${ }^{125}$ I-TSP and ${ }^{131} \mathrm{I}-\mathrm{Plg}$, forming a trimolecular complex (Table II). No inhibition of the binding of one ligand by the presence of the other was seen. In these experiments, EACA eluted $42.6 \%$ of the TSP from the trimolecular complexes, compared with $12.4 \%$ from the bimolecular HRGP-TSP complexes $(P<0.05)$. These data suggest that trimolecular complex formation occurred as a result both of TSP-Plg complexes binding to HRGP via the Plg LBS (EACA-elutable TSP) and of TSP and Plg binding to separate binding domains on the HRGP molecule (EACA-nonelutable TSP).

We confirmed complex formation in a third system using the technique of rocket immunoelectrophoresis. With this assay we have previously shown that Plg mixed with TSP, when electrophoresed into anti-Plg-containing antibody agar, moved more rapidly than $\mathrm{Plg}$ alone and formed an anodally moving sharp peak that contained the TSP-Plg complex (21). We have now shown that when radiolabeled HRGP was included in the TSP-Plg mixture and similarly electrophoresed, radioactivity was detected in the rapid peak (Fig. 4), demonstrating a trimolecular complex.

These studies do not permit accurate measurement of stoichiometric relations. Previously, however, we showed, by using sucrose density ultracentrifugation, that the stoichiometry of the TSP-HRGP complex was $\sim 3.5$ HRGP molecules/ molecule of TSP (20). ELISA studies using TSP monomer showed comparable extent of bimolecular and trimolecular complex formation with HRGP and Plg compared with whole TSP, suggesting that the unit of binding is the TSP monomer and that each TSP molecule may bind three HRGP and three Plg molecules.

To examine whether the trimolecular TSP-HRGP-Plg complex retained functional capability, we studied the ability of the complex to bind heparin (a function of HRGP) and to serve as a substrate for plasmin generation by TPA. Table II shows, using a ${ }^{35} \mathrm{~S}$-heparin probe, that the trimolecular complex retained the heparin-binding capacity of the bimolecular TSPHRGP complex and that it bound significantly more heparin than TSP alone.

Using a fluorometric plasmin substrate (D-val-leu-lys-AFC), we have demonstrated that significant amounts of plasmin were generated by TPA from both the bimolecular TSP-Plg and the trimolecular TSP-Plg-HRGP complexes compared with Plg added to fibronectin or VWF-coated microtiter wells (Fig. 5). Interestingly, plasmin was generated from the trimolecular complex at a more rapid rate than from the TSP-Plg bimolecular complex (Fig. 6), an effect observed at all Plg and HRGP concentrations tested. This augmentation can not be accounted for by an increase in Plg binding, as shown in Fig. $2 A$, and may reflect an additional interaction of HRGP with $\mathrm{Plg}$, via the lower affinity LBS of Plg, while both are complexed 
to TSP. It has been shown that interaction of omega aminocarboxylic acids, such as EACA, with the LBS of native glu$\mathrm{Plg}$ results in a change in the conformational state of that molecule and an increased rate of activation by Plg activators (in nonfibrin-containing systems) (39). HRGP can also interact with the Plg LBS and thus may have a similar effect.

Because fibrin is the most important positive modulator of TPA (37), a kinetic analysis was done to compare fibrin and TSP in their ability to promote Plg conversion to plasmin by TPA (Table IV). The fibrin kinetics were obtained using a ${ }^{125} \mathrm{I}$ fibrin plate assay (21). The TSP study was done in a nonfibrin system using a fluorometric plasmin substrate under otherwise similar experimental conditions; i.e., activation was measured in polystyrene wells coated with a film of protein $(4 \mu \mathrm{g} / \mathrm{ml}$ TSP or $6.5 \mu \mathrm{g} / \mathrm{ml}$ clotted fibrinogen). Like fibrin, TSP markedly decreased the $K_{\mathrm{M}}$ of activation compared with that in fluid phase; i.e., the TSP-Plg complex compared favorably to the fibrin-Plg complex in affinity for TPA $(0.085$ vs. $0.10 \mu \mathrm{M})$. The overall catalytic efficiency $\left(k_{\mathrm{cat}} / K_{\mathrm{M}}\right)$ in the presence of TSP was increased thus by 35 -fold compared with fluid phase, while that in the presence of fibrin was increased 400 -fold. This difference between TSP and fibrin was due to the additional effect of fibrin of a 15-fold increase in $k_{\text {cat }}$. Thus, compared with fluid phase, the solid phase TSP-Plg interaction resulted in a 40-fold increase in reaction rate, which was approximately 10-fold less than that seen on a fibrin surface. We conclude that fibrin is a more efficient surface for $\mathrm{Plg}$ activation than TSP

The physiological significance of the TSP-HRGP-Plg trimolecular complex is thus complicated and remains to be fully clarified. We previously raised the possibility that TSP on the activated platelet surface may regulate heparin action by binding HRGP (20). Since TSP also binds Plg and inhibits its activation by TPA on a fibrin clot (21), we have speculated that localization of $\mathrm{Plg}$ on the activated platelet surface may play a role in modulating fibrinolysis in the microenvironment of the platelet plug. Thus, in a focal region of active hemostasis, the sum total of these molecular associations would be prothrombotic, leading to increased deposition of fibrin.

The data presented in this paper also suggest that TSP itself can serve as an alternative "surface," other than fibrin, for TPA-induced Plg activation and that this effect is augmented by the inclusion of HRGP within the complex. In view of the broad distribution of TSP in different cell systems, including endothelial cells (6), smooth muscle cells $(7,40)$, fibroblasts (8), and monocytes (9), as well as the extracellular matrix (8), it seems reasonable that the TSP-HRGP-Plg complex could assemble in focal areas independent of the presence of fibrin. At sites of inflammation, tumor cell migration, and implantation as well as trophoblast implantation, TPA synthesis and secretion are known to be increased (41-44). Thus, Plg immobilized on TSP at such sites could generate plasmin in a fibrin-free environment in a kinetically favorable manner. It is thus likely that the TSP-HRGP-Plg macromolecular complex may effect different physiological endpoints in different microenvironments.

\section{Acknowledgments}

We thank Miss Barbara Ferris for excellent technical assistance.

Dr. Silverstein is the recipient of Physician Scientist Award K11HLAM1442 from the National Heart, Lung and Blood Institute.
This work was supported by grant HL18828 (Specialized Center of Research in Thrombosis) from the National Institutes of Health.

\section{References}

1. Lawler, J. W., H. S. Slayter, and J. E. Coligan. 1978. Isolation and characterization of a high molecular weight glycoprotein from human blood platelets. J. Biol. Chem. 253:8609-8616.

2. Baenziger, N. L., G. N. Brodie, and P. W. Majerus. 1971. Isolation and properties of a thrombin sensitive protein of human platelets. Proc. Natl. Acad. Sci. USA. 68:240-243.

3. Hagen, I. 1975. Effects of thrombin on washed human platelets: changes in subcellular fractions. Biochim. Biophys. Acta. 392:242-254.

4. Gerrard, J. M., D. R. Phillips, G. H. Rao, E. F. Plow, D. A. Walz, R. Ross, L. A. Harker, and J. G. White. 1980. Biochemical studies of two patients with the grey platelet syndrome: selective deficiency of platelet $\alpha$-granules. J. Clin. Invest. 66:102-109.

5. Phillips, D. R., L. K. Jennings, and H. R. Prasana. 1980. Calcium mediated association of glycoprotein-G (thrombin-sensitive protein, thrombospondin) with human platelets. J. Biol. Chem. 255: 11629-11632.

6. Mosher, D. F., M. J. Doyle, and E. A. Jaffe. 1982. Synthesis and secretion of thrombospondin by cultured human endothelial cells. J. Cell Biol. 93:343-348.

7. McPherson, J., H. Sage, and P. Bornstein. 1981. Isolation and characterization of a glycoprotein secreted by aortic endothelial cells in culture: apparent identity with platelet thrombospondin. J. Biol. Chem. 256:11330-11336.

8. Jaffe, E. A., J. T. Ruggiero, L. L. K. Leung, M. J. Doyle, P. J. McKeown-Longo, and D. F. Mosher. 1983. Cultured human fibroblasts synthesize and secrete thrombospondin and incorporate it into the extracellular matrix. Proc. Natl. Acad. Sci. USA. 80:998-1002.

9. Jaffe, E. A., J. T. Ruggiero, and D. Falcone. 1985. Monocytes and macrophages synthesize and secrete thrombospondin. Blood. 65: 79-84.

10. Hynes, R. O., and K. M. Yamada. 1982. Fibronectins: multifunctional modular glycoproteins. J. Cell Biol. 95:369-377.

11. Lawler, J. W., and H. S. Slayter. 1981. The release of heparin binding peptides from platelet thrombospondin by proteolytic action of thrombin, plasmin and trypsin. Thromb. Res. 22:267-279.

12. Dixit, V. M., G. A. Grant, W. A. Frazier, and S. A. Santoro. 1984. Isolation of the fibrinogen binding region of platelet thrombospondin. Biochem. Biophys. Res. Commun. 119:1075-1079.

13. Dixit, V. M., G. A. Grant, S. A. Santoro, and W. A. Frazier. 1984. Isolation and characterization of a heparin binding domain from the amino terminus of platelet thrombospondin. J. Biol. Chem. 259: 10100-10105.

14. Jaffe, E. A., L. L. K. Leung, R. L. Nachman, R. I. Levin, and D. F. Mosher. 1982. Thrombospondin is the endogenous lectin of human platelets. Nature (Lond.). 295:246-248.

15. Gartner, T. K., M. J. Doyle, and D. F. Mosher. 1983. AntiTSP serum inhibits the endogenous lectin activity of A23187 activated and gamma-thrombin activated human platelets. Thromb. Haemostasis. 50:124 (abstr.)

16. Leung, L. L. K. 1984. The role of thrombospondin in platelet aggregation. J. Clin. Invest. 74:1764-1772.

17. Leung, L. L. K., and R. L. Nachman. 1982. Complex formation of platelet thrombospondin with fibrinogen. J. Clin. Invest. 70:542549.

18. Lahav, J., M. A. Schwartz, and R. O. Hynes. 1982. Analysis of platelet adhesion with a radioactive chemical crosslinking reagent: interaction of thrombospondin with fibronectin and collagen. Cell. 31 : 253-262.

19. Mumby, S. M., G. J. Raugi, and P. Bornstein. 1984. Interactions of thrombospondin with extracellular matrix proteins: selective binding to type V collagen. J. Cell Biol. 98:646-652.

20. Leung, L. L. K., R. L. Nachman, and P. C. Harpel. 1984. 
Complex formation of platelet thrombospondin with histidine rich glycoprotein. J. Clin. Invest. 73:5-12.

21. Silverstein, R. L., L. L. K. Leung, P. C. Harpel, and R. L. Nachman. 1984. Complex formation of platelet thrombospondin with plasminogen: modulation of activation by tissue activator. J. Clin. Invest. 74:1625-1633.

22. Haupt, H., and N. Heimburger. 1972. Humanserumproteine mit hoher Affinitat zu Carboxymethycellulose I. Hoppe-Seyler's Z. Physiol. Chem. 353:1125-1132.

23. Leung, L. L. K., P. C. Harpel, R. L. Nachman, and E. M. Rabellino. 1983. Histidine-rich glycoprotein is present in human platelets and is released upon thrombin stimulation. Blood. 62:10161021.

24. Morgan, W. T. 1981. Interactions of the histidine-rich glycoprotein of serum with metals. Biochemistry. 20:1054-1061.

25. Lijnen, H. R., D. B. Rylatt, and D. Collen. 1983. Physicochemical, immunochemical, and functional comparison of human histidine-rich glycoprotein and autorosette inhibition factor. Biochem. Biophys. Acta. 742:109-115.

26. Lijnen, H. R., M. Hoylaerts, and D. Collen. 1983. Heparin binding properties of human histidine rich glycoprotein. J. Biol. Chem. 255:3803-3808.

27. Lijnen, H. R., B. Van Hoef, and D. Collen. 1984. Histidinerich glycoprotein modulates the anticoagulant activity of heparin in human plasma. Thromb. Res. 51:266-268.

28. Lijnen, H. R., H. Hoylaerts, and D. Collen. 1980. Isolation and characterization of a human plasma protein with high affinity for the lysine binding sites in plasminogen. J. Biol. Chem. 255:10214 10222.

29. Clezardin, P., J. L. McGregor, M. Manach, F. Robert, M Dechavanne, and K. J. Clemetson. 1984. Isolation of thrombospondin released from thrombin stimulated platelets by FPLC on an anion exchange Mono Q column. J. Chromatogr. 296:249-256.

30. Deutsch, D. G., and E. T. Mertz. 1970. Plasminogen: purification from human plasma by affinity chromatography. Science (Wash. DC). 170:1095-1096.

31. McConahey, P. J., and F. J. Dixon. 1966. A method of trace iodination of proteins for immunological studies. Int. Arch. Allergy Appl. Immunol. 29:185-189.
32. Fraker, P. J., and J. C. Speck, Jr. 1978. Protein and cell membrane iodinations with a sparingly soluble chloramine, 1,3,4,6 tetrachloro-3a-6adiphenyl-glycoluril. Biochem. Biophys. Res. Commun. 80:849-857.

33. Garvey, J. S., N. E. Cremer, and D. H. Sussdorf. 1977. Methods in Immunology. W. A. Benjamin, Inc., Reading, MA. Third ed. 7-39.

34. Voller, A., D. Bidwell, and A. Bartlett. 1976. Microplate enzyme immunoassays for the immunodiagnosis of virus infections. In Manual of Clinical Immunology. N: R. Rose and H. Friedman, editors. Am. Assoc. of Microbiol. 506-512.

35. Wilkinson, G. N. 1961. Statistical estimations in enzyme kinetics. Biochem. J. 80:324-332.

36. Kosow, D. P., B. Furie, and H. Forastieri. 1974. Activation of Factor X: kinetic properties of the reaction. Thromb. Res. 4:219-227.

37. Hoylaerts, M., D. C. Rijken, H. R. Lijnen, and D. Collen. 1982. Kinetics of the activation of plasminogen by human tissue plasminogen activator: role of fibrin. J. Biol. Chem. 257:2912-2919.

38. Kolb, W. P., and L. M. Kolb. 1983. Antithrombin III binding to C5b-9 attack complexes of human complement: dissociation of a modified antithrombin III derivative subsequent to complex formation. Biochemistry. 22:496-504.

39. Banyai, L., and L. Patthy. 1984. Importance of intramolecular interactions in the control of fibrin affinity and activation of human plasminogen. J. Biol. Chem. 259:6466-6471.

40. Raugi, G. J., S. M. Mumby, D. Abbott-Brown, and P. Bornstein 1982. Thrombospondin: synthesis and secretion by cells in culture. $J$. Cell Biol. 95:351-354.

41. Reich, E. 1978. Activation of plasminogen: a widespread mechanism for generating localized extracellular proteolysis. In Biological Markers of Neoplasia: Basic and Applied Aspects. R. W. Rudden, editor. Elsevier/North Holland, Amsterdam. 491-500.

42. Unkeless, J. C., S. Gordon, and E. Reich. 1974. Secretion of plasminogen activator by stimulated macrophages. J. Exp. Med. 139: 834-850.

43. Wilson, E. L., and E. B. Dowdle. 1978. Secretion of plasminogen activator by normal reactive and neoplastic human tissues in vitro. Int. J. Cancer. 22:390-399.

44. Strickland, S., E. Reich, and M. I. Sherman. 1976. Plasminogen activator in early embryogenesis: enzyme production by trophoblast and parietal endoderm. Cell. 9:231-240. 